\title{
Production of putrescine-capped stable silver nanoparticle: its characterization and antibacterial activity against multidrug-resistant bacterial strains
}

\author{
Saswati Saha $^{1} \cdot$ Bhaskar Gupta $^{2} \cdot$ Kamala Gupta $^{3} \cdot$ Mahua Ghosh Chaudhuri $^{1}$
}

Received: 22 December 2015/Accepted: 19 March 2016/Published online: 12 April 2016

(C) The Author(s) 2016. This article is published with open access at Springerlink.com

\begin{abstract}
Integration of biology with nanotechnology is now becoming attention-grabbing area of research. The antimicrobial potency of silver has been eminent from antiquity. Due to the recent desire for the enhancement of antibacterial efficacy of silver, various synthesis methods of silver in their nano dimensions are being practiced using a range of capping material. The present work highlights a facile biomimetic approach for production of silver nanoparticle being capped and stabilized by putrescine, possessing a diameter of $10-25 \pm 1.5 \mathrm{~nm}$. The synthesized nanoparticles have been analyzed spectrally and analytically. Morphological studies are carried out by high-resolution transmission electron microscopy and crystallinity by selected area electron diffraction patterns. Moreover, the elemental composition of the capped nanoparticles was confirmed by energy-dispersive X-ray spectroscopy
\end{abstract}

Electronic supplementary material The online version of this article (doi:10.1007/s13204-016-0528-9) contains supplementary material, which is available to authorized users.

Kamala Gupta

kamalagupta@gmail.com

$\triangle$ Mahua Ghosh Chaudhuri

mahua_ch@yahoo.com

Saswati Saha

sahasaswati27@gmail.com

Bhaskar Gupta

bhaskarzoology@gmail.com

1 School of Materials Science and Nanotechnology, Jadavpur University, Kolkata 700032, India

2 Department of Zoology, Government General Degree College, Singur, Hooghly, West Bengal, India

3 Department of Botany, Government General Degree College, Singur, Hooghly, West Bengal, India analysis. A comparative study (zone of inhibition and minimum inhibitory concentration) regarding the interactions and antibacterial potentiality of the capped silver nanoparticles with respect to the bare ones reveal the efficiency of the capped one over the bare one. The bacterial kinetic study was executed to monitor the interference of nanoparticles with bacterial growth rate. The results also highlight the efficacy of putrescine-capped silver nanoparticles as effective growth inhibitors against multi-drug resistant human pathogenic bacterial strains, which may, thus, potentially be applicable as an effective antibacterial control system to fight diseases.

Keywords Antibacterial activity $\cdot$ Biomimic $\cdot$ Multi-drug resistant · Polycationic $\cdot$ Putrescine capping - Silver nanoparticles

\section{Introduction}

Nanomaterials are the keystone of the nanoscience and nanotechnology research. The knowledge of merging nanomaterials in the area of biology and its applications is potentially revolutionizing in many fields of science and technology. Over past few decades, noble metal nanoparticles have been eliciting much area of interest to many of the researchers due to their unique optical, electronic, magnetic, mechanical and chemical properties which are extensively diverse from those of the bulk materials (Mazur 2004; Rao et al. 2002). Since ancient historic period, silver salts have been used as an effective antimicrobial agent. But, with an increased emergence of multiple antibiotic resistant microorganisms, much emphasis is being given towards the usage of nanosilver as antimicrobials, due to the inability of microorganisms in developing 
resistance against silver ions (Rai et al. 2012; Muhling et al. 2009). The preferential use of spherical silver nanoparticles over its other shapes, as an antimicrobial agent, is due to their high reactivity for their large surface area to volume ratio (Roduner 2006). Albeit, recently silver nanoparticles have been studied as biomarkers (Jain et al. 2008; Schoefield et al. 2006) for their localized surface plasmon resonance. They are mostly popular for their antimicrobial applications like, wound dressings (Tian et al. 2007), water treatment (Lv et al. 2009), fabrics and textile processing (Vo Ke Thanh and Phuong Phong 2009) and more recently in agronomy (Mandeh et al. 2012; Abdi et al. 2008; Saha et al. 2015).

Silver in their nano dimension has been reported to show immense antimicrobial activity without generation of any resistant variety strains. Silver possessing an oligodynamic property is toxic to microbes at their lower concentrations but not to human cells and for this reason, it is considered as an environment friendly antimicrobial agent. The mechanism regarding antibacterial activity of silver nanoparticles is still under scientific debate. Many authors rely on the fact that silver cations are released from nanosilver (Kittler et al. 2010). Consequently, diverse ranges of stabilizing or capping materials are used during the synthesis of silver nanoparticles for their controlled release (Liu et al. 2010). Arrays of physical, chemical and biological methods have been used to synthesize and stabilize silver nanoparticles (Tolaymat et al. 2010; Saha et al. 2010, 2011; Roy et al. 2015). Out of these methods, biosynthesis and biomimetic synthesis processes are most extensively accepted in recent years (Vijayaraghavan and Nalini 2010; Mohanpuria et al. 2008). To reduce environmental pollution, usages of synthetic organic stabilizers were avoided (Bar et al. 2009). Due to the preferential requirement of the biomolecules from the lower bio-organisms (bacteria) to higher (plants) as compared to those of synthetic ones, an ensemble of biogenic substances (macro and micro) like carbohydrate, protein, lipid, amino acids, DNA, flavonoids, etc. have been reported in stabilizing silver nanomaterials biomimetically (Amato et al. 2011; Xie et al. 2007).

Putrescine (put), on the other hand, is one of the most familiar natural occurring polyamine (diamine) which is ubiquitously present in plants and other living organisms. They can exist as secondary metabolites, possessing evenly distributed di-amine groups for which they play a vital role in plethora of cellular processes including physiological stress adaptation, programmed cell death and development (Bagni and Pistocchi 1991; Flores et al. 1989). Moreover, putrescine serves with an excellent role in stress adaptation in plants at extreme conditions like drought, low $\mathrm{pH}$, osmotic shock, etc. (Young and Galston 1983; Flores and Galston 1982) which is beneficial for the amelioration in field of agronomy. Furthermore, these water-soluble polyamines are strongly basic, aliphatic multivalent cationic nitrogenated molecule which acquires a highly protonated primary amino groups at physiological $\mathrm{pH}$ (Gupta et al. 2013, 2014). Owing to the high affinity of bacterial cells towards these polycationic aliphatic amines, like other cationic synthetic polymers, they may be able to interact with the negatively charged phospholipids (membrane heads) and membrane bound proteins, ion channels, leading to alteration of packing arrangement of the bacterial cells (Schuber 1989). However, there are practically no reports found on usage of putrescine as the capping agent and its advantage through biomimic activity as a better antimicrobial agent mutually along with silver (in nanodimensions). So, to ascertain the synergistic effect of silver nanoparticles along with plant natural polyamines against bacteria, in the present work, we explore a biomimetic capping procedure that permits us to stabilize silver nanoparticles with plant natural polyamine, attributing polycationic (di-amine) moieties to investigate their successful usage as antibacterial agents against some pathogenic bacterial strains of public concern.

\section{Materials and methods}

\section{Materials}

Silver nitrate $\left(\mathrm{AgNO}_{3}\right)(99.9 \%)$, sodium borohydrite $\left(\mathrm{NaBH}_{4}\right)(98 \%)$, putrescine $(99 \%)$ were purchased from Sigma-Aldrich. Nutrient agar (NA), nutrient broth (NB) and agar (for bacterial culture) were purchased from Himedia. All reagents were received and used in the laboratory without further purification. De-ionized water (DIwater) was purchased from Hydro Lab.

\section{Methods}

\section{Synthesis of bare and putrescine-stabilized silver nanoparticles}

In this experiment, two sets were taken separately, one for the synthesis of bare silver nanoparticles (bare-AgNPs) and another one for putrescine-capped silver nanoparticles (put-AgNPs). In each of the sets, $20 \mathrm{ml}$ of $1 \mathrm{mM} \mathrm{AgNO}$ solution was added slowly and drop wise to ice-cold solution of $60 \mathrm{ml}$ of $2 \mathrm{mM} \mathrm{NaBH}_{4}$ with constant rigorous stirring using a magnetic stirrer. All the solutions were made using DI-water. A lot of heat was generated during the reaction and the formation of effervescence was observed due to the liberation of hydrogen $\left(\mathrm{H}_{2}\right)$. The $\mathrm{Ag}^{+}$ ions of $\mathrm{AgNO}_{3}$ were reduced to $\mathrm{Ag}^{0}$ states in a reducing environment of borohydrite. 
$\mathrm{AgNO}_{3}+\mathrm{NaBH}_{4} \rightarrow \mathrm{Ag}^{0}+\mathrm{H}_{2} \uparrow+\mathrm{B}_{2} \mathrm{H}_{6}+\mathrm{NaNO}_{3}$

The change in color occurred slowly from colorless transparent liquid to light yellow on reaction. Stirring under ice-cold condition (maintained for slow and uniform reduction) was continued till the end of effervescence formation.

\section{Formation of bare silver nanoparticles (bare-AgNPs)}

One of the sets was left for constant stirring without addition of any capping material. So, the $\mathrm{Ag}^{0}$ seeds were allowed to grow or agglomerate through Ostwald's ripening method to form unstable bare-AgNPs giving a straw yellow to brownish yellow color which lasted for only 2 months.

\section{Formation of putrescine-stabilized silver nanoparticle (put-AgNPs)}

For the other set, $0.5 \mathrm{mM}$ of putrescine was prepared from the stock solution of $1 \mathrm{mM}$ using autoclaved DI-water which was then added drop wise to the naked $\mathrm{Ag}^{0}$ seeds just after its formation under constant stirring to control seed growth and stabilize resulting particles of nano dimensions. The stirring was continued until a slight visual change in color occurred, thus resulting in formation of stable putrescine-capped silver nanoparticles (put-AgNPs) maintaining a $\mathrm{pH}$ at 8.7. These newly synthesized capped nanoparticles were recovered after centrifugation at $19,000 \mathrm{rpm}$ for $40 \mathrm{~min}$. Figure 1 shows the schematic representation of the whole synthesis process of the silver nanoparticles (both bare-AgNPs and put-AgNPs).

\section{Characterization of the synthesized nanosilver}

The natural put-AgNPs were washed thoroughly with DIwater by repeated centrifugation at their above-mentioned respective rpm and time. The recovered nanoparticles were set for characterization both by spectral and analytical methods. The absorption spectra were recorded by using Jasco $650 \mathrm{UV}$-vis spectrophotometer. Their morphologies were confirmed by high-resolution transmission electron microscopy (HRTEM) images, using JEOL TEM-2100 where the samples were prepared on carbon-coated copper grid. Their hydrodynamic size distributions and zeta potential were measured by dynamic light scattering (DLS) using Delsa NanoC Zetasizer (Beckman Coulter Instrument). The putrescine capping of the put-AgNPs was confirmed by fourier transform infrared (FTIR) spectroscopy, using Jasco 6300 instrument with ATR mode. The elemental analyses of the nanoparticles were carried out by the EDX analysis (JSM-6360).

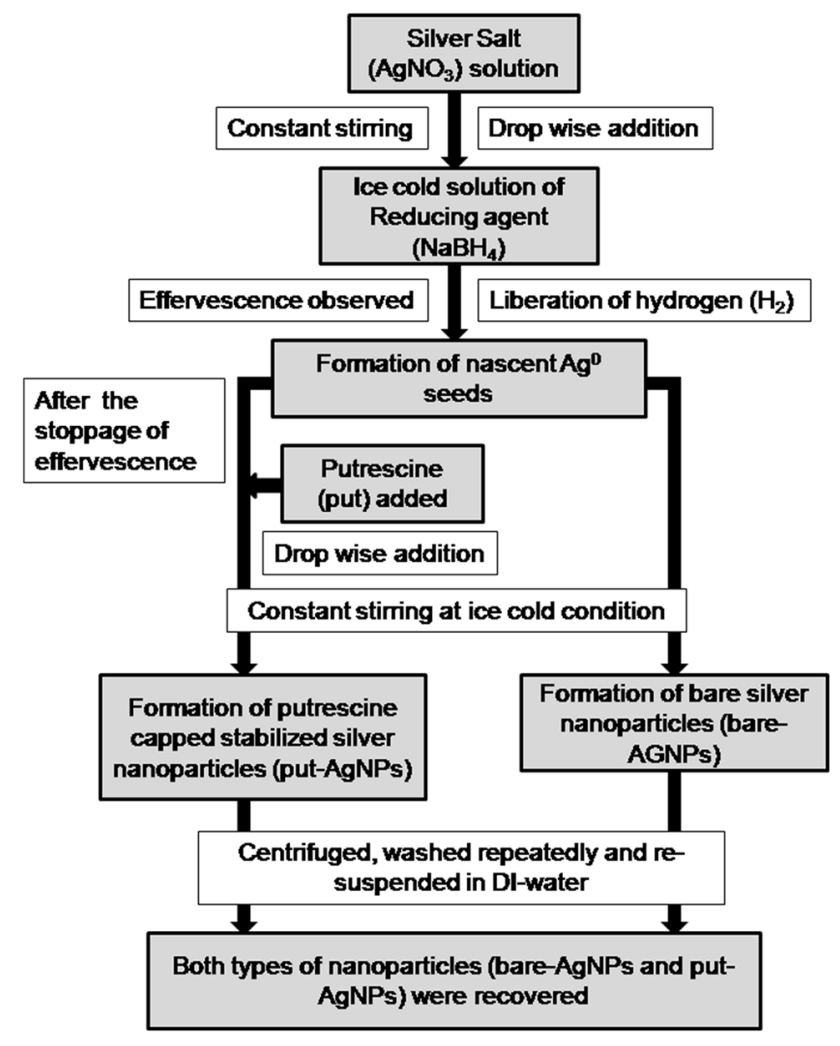

Fig. 1 Schematic representation of the synthesis process of silver nanoparticles

\section{Bacterial susceptibility study (zone of inhibition)}

The bacterial susceptibility to different put-AgNPs was evaluated against 7 (the former 4 are Gram positive and the later 3 are Gram negative) different multidrug-resistant pathogenic microbial strains viz., Bacillus cereus (ATCC 10987), Bacillus subtilis (ATCC 6633), Micrococcus luteus (ATCC 10240), Staphylococcus aureus (ATCC 25923), Enterobacter cloacae (ATCC 13047), Serratia marcescens (ATCC 13880) and Shigella dysentery (ATCC 9361) by disc diffusion method. Their effects were compared along with the bare-AgNPs and silver ions (as silver nitrate). On the other hand, pure putrescine $(0.5 \mathrm{mM})$ was tested exclusively (as negative controls) for comparison of its antimicrobial potentiality against the same microbial strains. The inocula of each bacterial strain were prepared by growing them in liquid $\mathrm{NB}$ medium at $37^{\circ} \mathrm{C}$ with constant shaking for $24 \mathrm{~h}$ containing $\sim 10^{7}-10^{8} \mathrm{CFU} / \mathrm{ml}$ of bacteria in each batch. Then bacterial strains were cultured in the NB agar plates followed by placing of three discs loaded with put-AgNPs, bare-AgNPs and silver ions (as $\mathrm{AgNO}_{3}$ ), respectively, and set for disc diffusion antibacterial assay. The antibacterial effects were elucidated and compared by measuring the zone of inhibition formed by the different silver nanoparticles at $50 \mu \mathrm{g} / \mathrm{ml}$ concentration. This experiment has been replicated thrice. 


\section{Minimum inhibitory concentration study}

Each of the seven different bacterial strains was cultured in $10 \mathrm{ml}$ of NB medium (as controls) separately. Similar sets of bacterial strains were also grown for treating with silver nanoparticles (both capped and bare) one at a time of different concentrations. Individual bacterial strains each in $10 \mathrm{ml} \mathrm{NB}$ were treated separately with silver nanoparticles (one type at a time) of concentrations 0 (control), 10, $20 \ldots$ up to $60 \mu \mathrm{g} / \mathrm{ml}$. The minimum inhibitory concentrations (MIC) for each of the seven bacterial strains were established after overnight incubation (at $37^{\circ} \mathrm{C}$ ) of their liquid culture by measuring the optical density at different concentrations of nanosilver (using McFarland Standards). Three replicates of this experiment have been performed.

\section{Morphological study of the put-AgNPs treated bacteria}

Each of the seven different bacterial strains, previously treated with put-AgNPs at their respective MIC values was set for morphological characterization under scanning electron microscopy (SEM). Aliquots of each of bacterial cultures incubated overnight (at $37^{\circ} \mathrm{C}$ ) were drop-cast on piranha-treated glass slide pieces and left to dryness within desiccators. The vacuum-dried samples were observed under SEM.

\section{Bacterial growth kinetics under inhibition by AgNPs}

Bacterial growth kinetics was monitored by the endpoint turbidity-based measurements to evaluate the influence of silver nanoparticles at different phases of bacterial cell growth and multiplication. All the seven bacterial strains were selected to explore the effect of nanosilver on their total growth period. For this $100 \mu \mathrm{l}$ of inocula of one type of bacterial strains (containing $\sim 10^{7}-10^{8} \mathrm{CFU} / \mathrm{ml}$ ) was taken from its respective NB growth medium and inoculated to $50 \mathrm{ml}$ of NB (containing bare-AgNPs at its corresponding MIC specific to that strain) such that the final concentration of the total solution reach its MIC of that type of nanosilver. Likewise, the remaining other bacterial strains were inoculated in NB (containing their respective MICs of bare-AgNPs). Similarly, all the seven bacterial strains were inoculated in the NB media containing putAgNPs (at their respective MICs). So, altogether seven different bacterial strains were inoculated separately in NB media containing bare-AgNPs and put-AgNPs one at a time. These inoculated flasks (seven bacterial strains $\times$ two types of AgNPs) were set for incubation at $37{ }^{\circ} \mathrm{C}$ for $24 \mathrm{~h}$ with constant shaking. Aliquots of $2 \mathrm{ml}$ of each sample were withdrawn at a regular interval of $1 \mathrm{~h}$ and absorbance (optical density/OD) was measured at $625 \mathrm{~nm}$. This experiment has been repeated three times.
All the OD values were plotted against time (hours) shown in Fig. 8.

\section{Results and discussions}

\section{Nanosilver characterization}

The formation of the synthesized silver nanoparticles (bare-AgNPs and put-AgNPs) were initially identified by the color change (inset of Fig. 2) and spectrally visualized by UV-vis spectrophotometer. The stabilized put-AgNPs showed a specific sharp resonance (SPR) at $394 \mathrm{~nm}$, whereas, a very broad SPR has been recorded for the unstable bare-AgNPs (Fig. 2). This is mainly due to the collective oscillation of free conduction electrons induced by an interacting electromagnetic field in case of formation of stable homogeneous put-AgNPs (Nanocomposix silver nanoparticles: optical properties). But in case of unstable bare-AgNPs the peak broadens due to mechanism of Ostwald's ripening. As observed from HRTEM images, the synthesized capped nanoparticles (put-AgNPs) were more or less spherical, well dispersed, uniform and attained a hydrodynamic diameter of $10-25 \pm 1.5 \mathrm{~nm} \quad$ (Fig. 3a) which was confirmed by DLS measurements (Fig. 3d). The clear and uniform lattice fringes (shown in Fig. 3c) confirmed that the spherical particles are highly crystallized containing a lattice spacing of $0.25 \mathrm{~nm}$ which corresponds to (111) planes of silver. The results show that the dominant faces of silver spheres are (111). The ring patterns of face centered cubic (fcc) silver nanocrystallite planes were identified by the selected area electron diffraction (SAED) patterns (Fig. 3b) by directing the electron beam perpendicular to one of the spheres, which can be indexed to the (111), (200), (220) and (311) reflections of metallic silver (JCPDS file no. 04-0783). The elemental composition of synthesized put-AgNPs was further confirmed by EDX data (Fig. 4) reporting the presence of Silver (Ag L $\alpha$ at $2.989 \mathrm{keV})$, Carbon ( $\mathrm{C} \mathrm{K} \alpha$ at $0.277 \mathrm{keV}$ ) and Nitrogen ( $\mathrm{N} \mathrm{K} \alpha$ at $0.392 \mathrm{keV}$ ) confirming the presence of capping material putrescine in the put-AgNPs nanocrystallites. The recorded zeta potential of the bare silver nanoparticle is -15.30 and that of the synthesized silver nanoparticles after polyamine capping were 39.77 (put-AgNPs), the results which also confirm the formation of stable capped silver nanoparticles in suspension after capping (Malvern Instruments Ltd.).

\section{FTIR analysis}

Evidences regarding the capping and stabilization of the synthesized silver nanoparticle by polyamine (putrescine) were accomplished by the FTIR spectroscopic 


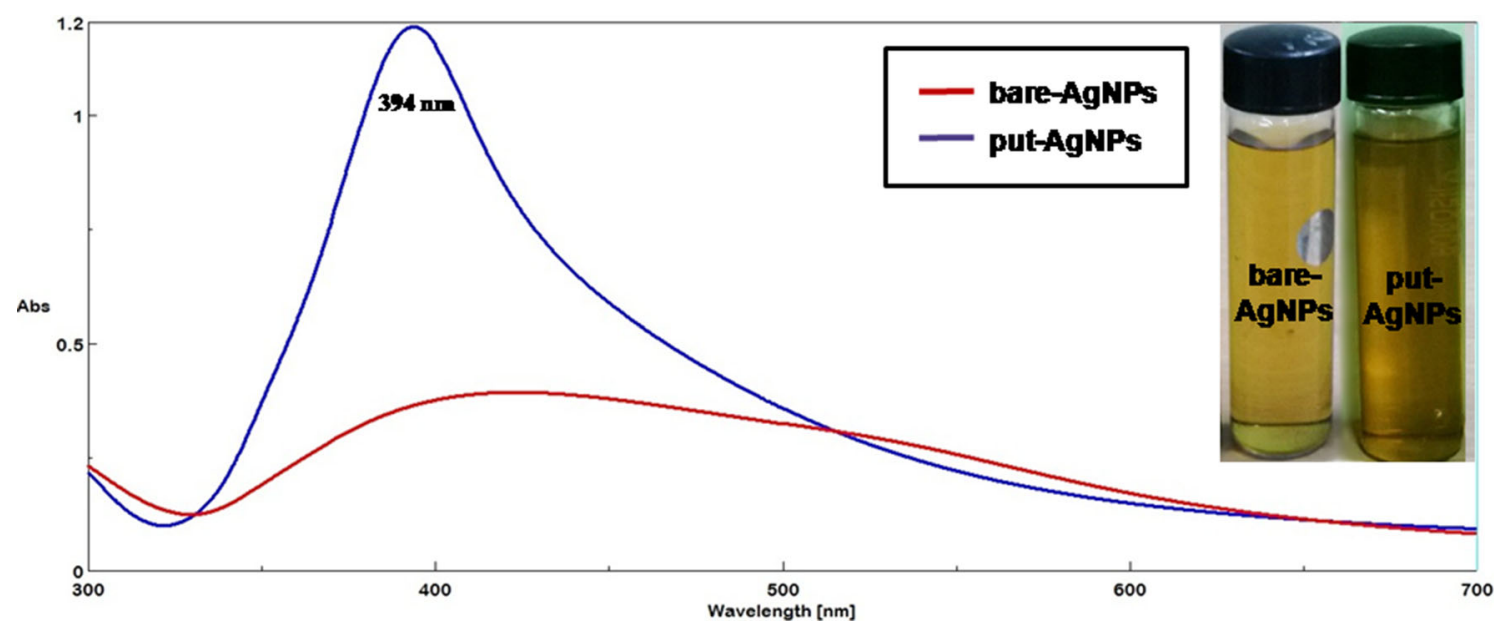

Fig. 2 UV-visible spectra of the DI-water dispersed silver nanoparticles (bare-AgNPs and put-AgNPs) along with the change in color after formation (inset)

Fig. 3 Morphological studies of put-AgNPs. a HRTEM micrographs of put-AgNPs along with their, b SAED patterns, $\mathbf{c}$ the uniformity of lattice fringes of the spherical nanoparticle and

d hydrodynamic diameter by DLS
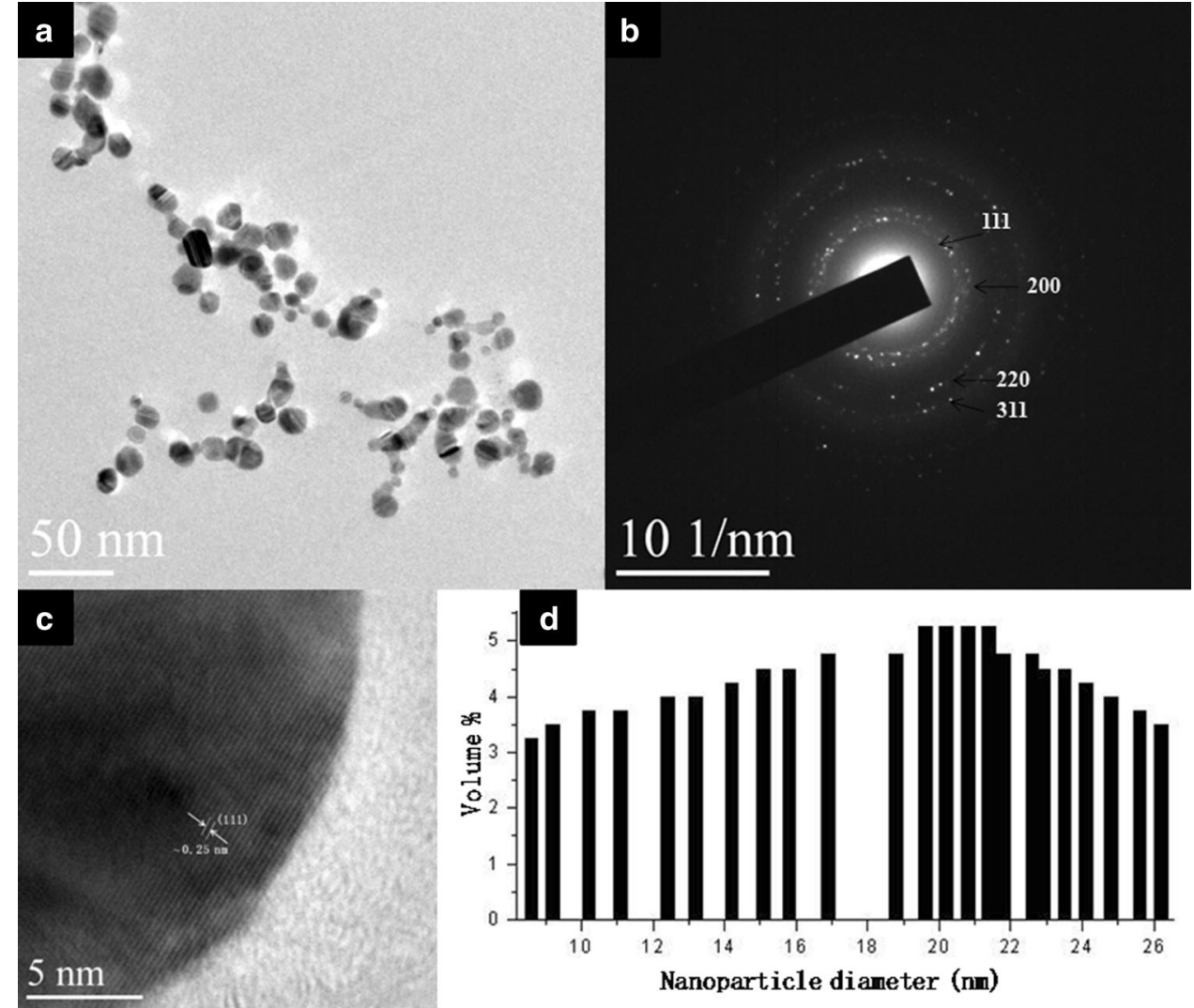

measurements. In Fig. 5, formation of a strong band is visible at $3495-3312 \mathrm{~cm}^{-1}$ representing the $\mathrm{N}-\mathrm{H}$ stretching of the primary aliphatic amines which is blue shifted after capping (put-AgNPs) than the small peak at $3367 \mathrm{~cm}^{-1}$ of pure putrescine (pure-put). Another strong band at $1572 \mathrm{~cm}^{-1}$ representing the $\mathrm{N}-\mathrm{H}$ bending (scissoring) vibrations of putrescine, which is blue shifted to $1633 \mathrm{~cm}^{-1}$. This may infer the interaction and formation of co-ordinate bonds with the lone pair electrons of the primary $\mathrm{NH}_{2}$ groups of putrescine with the Ag. Other strong bands at 2923 and $2848 \mathrm{~cm}^{-1}$ may correspond to the asymmetrical $\left(v_{\mathrm{as}} \mathrm{CH}_{2}\right)$ and symmetrical $\left(v_{\mathrm{s}} \mathrm{CH}_{2}\right)$ stretching vibrations of the $\mathrm{CH}_{2}$ groups, whereas, bands at $1435 \mathrm{~cm}^{-1}$ may denote the scissoring $\left(\delta_{\mathrm{s}} \mathrm{CH}_{2}\right)$ and at $1345 \mathrm{~cm}^{-1}$ denote twisting and wagging vibrations of $\mathrm{CH}_{2}$ groups of pure-put which is being reduced after the capping. Another 
Fig. 4 EDX analysis of putAgNPs along with their composition in percentage
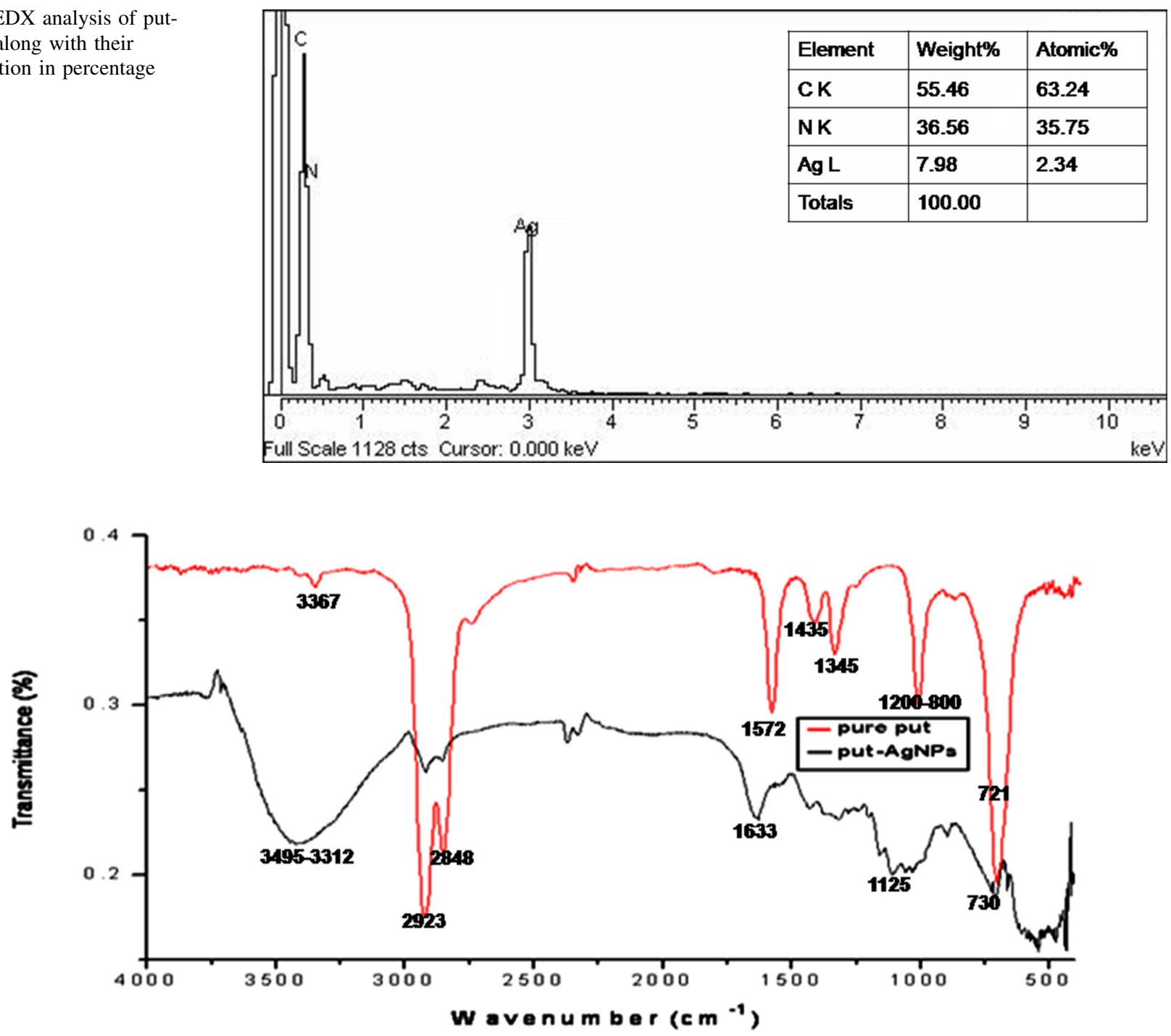

Fig. 5 FTIR spectral analysis of the synthesized capped put-AgNPs compared with the capping material pure putrescine

small band at $1125 \mathrm{~cm}^{-1}$ may represent the $\mathrm{C}-\mathrm{N}$ stretching vibrations were present after capping (in put-AgNPs). The bands at $1200-800 \mathrm{~cm}^{-1}$ may assign for the $\mathrm{C}-\mathrm{C}$ stretching vibrations (pure-put) which is being diminished after capping. The band at $721 \mathrm{~cm}^{-1}$ may be due to the $\mathrm{CH}_{2}$ rocking $\left(\rho \mathrm{CH}_{2}\right)$ vibrations which being minimized and slightly shifted to $730 \mathrm{~cm}^{-1}$ after capping (Kemp 1991; Silverstein 2012). The bands with slight blue shifts after capping of $\mathrm{Ag}^{0}$ with the putrescine are noteworthy. This may indicate the interaction (co-ordination bond) with nanosilver. Upon reacting with the reduced AgNP suspension, these were surface-exposed to amine groups (nitrogen lone pair electrons) of the polyamines and seem to be stabilized due to chemi-adsorption and/or co-ordination bond interactions, and also van der Waals forces. This indicated successful capping and thus formation of stable put-AgNPs.

\section{Antibacterial efficacy following bacterial susceptibility}

\section{Zone of inhibition}

The comparative study of bacterial zone of inhibition (diameter measured in $\mathrm{mm}$ ) formed due to its susceptibility to $\mathrm{AgNO}_{3}$, bare-AgNPs and synthesized polyamine-stabilized silver nanoparticles (put-AgNPs) were carried out. A significant difference in the zone of inhibition was observed against each of the seven bacterial strains illustrating enhanced antimicrobial activity by the newly synthesized capped nanosilver (put-AgNPs) than the other two (AgNO ${ }_{3}$, bare-AgNPs). The graphs (Fig. 6) for zone of inhibition, imply superiority of the newly synthesized putAgNPs in terms of antibacterial potentiality than the bareAgNPs and also $\mathrm{Ag}^{+}$ions $\left(\mathrm{AgNO}_{3}\right)$. Perhaps this may be 
due to the presence of cationic charges in the di-amine (putrescine) which might be responsible for the change in their binding efficiency to the negative moieties of bacterial membranes (Kawahara et al. 2000). On the other hand, the antimicrobial potentiality of pure putrescine (studied exclusively) was found to be nil.

\section{Minimum inhibitory concentration}

The minimum inhibitory concentrations (MIC) of the newly synthesized nanoparticles (capped and uncapped) against each of the seven bacterial strains namely $B$. cereus, $B$. subtilis, M. luteus, S. aureus, E. cloacae, S. marcescens and $S$. dysentery were established and represented as Table 1 . The data imply that put-AgNPs (capped) were more potential at their lower concentrations than compared to the bareAgNPs (uncapped). This better susceptibility shown by the polyamine-capped nanosilver may be due to the following reason. It is already known that silver nanoparticles in suspension release some $\mathrm{Ag}^{+}$ions into the media (bacterial liquid culture broth). These ions may cause a metal stress to the bacteria, influencing them to recognize and uptake cationic polyamine (Igarashi and Kashiwagi 1999) which are present in the media as capped-AgNPs. Thus, bacterial cells may internalize the capped nanosilver expressing biomimic activity. This will be lacking in case of bare-AgNPs, due to absence of the polyamine.

Although reported earlier that Gram-positive bacteria shows greater resistance to silver nanoparticles (Feng et al. 2000; Jung et al. 2008), but antimicrobial efficacy of the newly synthesized put-AgNPs against all the four Gram-positive bacterial strains (B. cereus, B. subtilis, M. luteus and S. aureus) is noteworthy. Interestingly, the MICs of put-AgNPs against all bacterial strains were in their minimum values than compared to the bare-AgNPs. In addition, the data table portrays the MIC values in all the cases were higher for the Grampositive strains than the Gram negative ones (E. cloacae, $S$. marcescens and $S$. dysentery). This may be due to the presence of thick peptidoglycan layer in case of Gram-positive strains, which hinders the nanoparticle entry (Sondi and SalopekSondi 2004; Nabil et al. 2000). But, here the positively charged capping of the polyamines might be valuable for binding with the teichoic acid groups and also the other negatively charged moieties present there, thus helping in the entry of nanoparticles (Guggenbichler et al. 1999).

\section{Morphological studies by SEM}

The SEM studies reveal an interaction of put-AgNPs (at the respective MIC) with the cell wall of the bacteria showing a distorted or irregular morphology which in turn might affect the cytosolic fluidity along with osmotic balance and causes cytoplasmic leakage. Thus, destroying the bacteria finally. The morphological changes of seven different putAgNPs treated bacterial strains; B. cereus, B. subtilis, M. luteus, S. aureus, E. cloacae, S. marcescens and S. dysentery were portrayed by SEM images (Fig. 7).

\section{Influence of AgNPs on bacterial growth kinetics}

The graphs (Fig. 8a-g) of bacterial growth decay over time when treated with synthesized silver nanoparticles (both

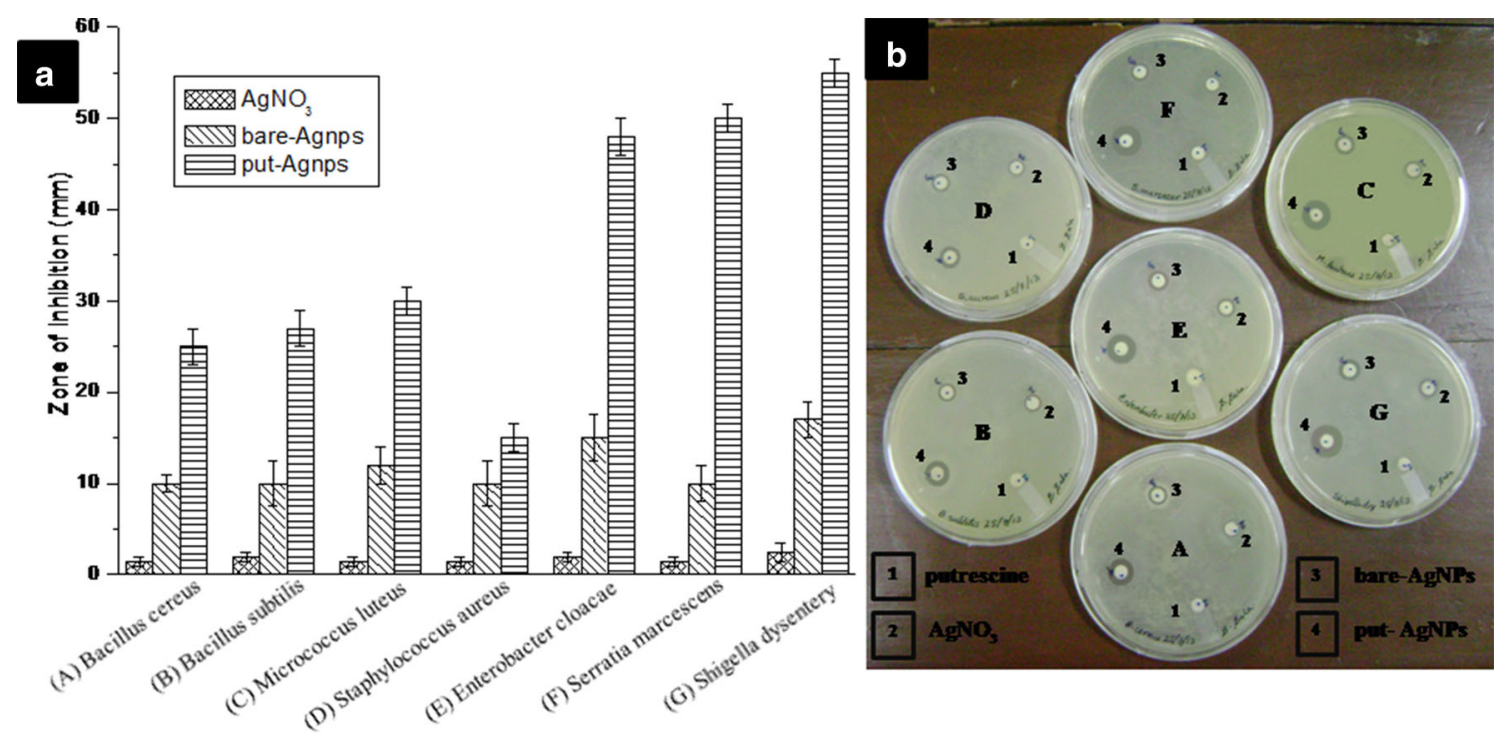

Fig. 6 a Comparative study of bacterial zone of inhibition (diameter in $\mathrm{mm}$ ) for $\mathrm{AgNO}_{3}$, bare-AgNPs, put-AgNPs, against Bacillus cereus, Bacillus subtilis, Micrococcus luteus, Staphylococcus aureus, Enterobacter cloacae, Serratia marcescens and Shigella dysentery. Three independent experiments were held. $\pm \mathrm{SD}$ are shown as the error bar. b Portraying of bacterial zone of inhibition by disc diffusion method 
Table 1 Minimum inhibitory concentration (MIC) values (in $\mu \mathrm{g} / \mathrm{ml}$ ) of bare-AgNPs, spd-AgNPs and spm-AgNPs against different multidrug-resistant (MDR) Gram-positive and Gram-negative bacteria

\begin{tabular}{lll}
\hline $\begin{array}{l}\text { MDR bacterial } \\
\text { strains }\end{array}$ & $\begin{array}{l}\text { MIC of } \\
\text { bare-AgNPs } \\
(\mu \mathrm{g} / \mathrm{ml})\end{array}$ & $\begin{array}{l}\text { MIC of } \\
\text { put-AgNPs } \\
(\mu \mathrm{g} / \mathrm{ml})\end{array}$ \\
\hline Bacillus cereus & 60 & 56 \\
Bacillus subtilis & 58 & 55 \\
Staphylococcus aureus & 59 & 57 \\
Micrococcus luteus & 60 & 58 \\
Enterobacter cloacae & 49 & 43 \\
Serratia marcescens & 50 & 46 \\
Shigella dysentery & 48 & 45 \\
\hline
\end{tabular}

Data represents the average of three replicate

uncapped and capped) at their respective MIC levels, portray a strong interference of nanosilver with bacteria at their exponential or log phase, compared to the control set (without nanosilver). The results at the 24th $\mathrm{h}$ of bacterial
Fig. 8 Effect of both uncapped and capped silver nanoparticles (bare-AgNPs and put-AgNPs) on bacterial growth kinetics of a Bacillus cereus, b Bacillus subtilis, c Micrococcus luteus, d Staphylococcus aureus, e Enterbacter cloacae, f Serratia marcescens and $\mathbf{g}$ Shigella dysentery. Three independent experiments were held. \pm SD are shown as the error bar

growth kinetics were not shown in the figure because there was no such denotable change in the optical density (OD) with respect to time. The results of experiment were repeated thrice and have been plotted along with their standard deviation values. Moreover, influence of nanosilver at the lag phase of the bacterial growth curve reveals more or less no distinguishable feature. The effect of nanosilver was observed at later part of the exponential phase of the Gram-positive strains (B. cereus, B. subtilis, $S$. aureus) than compared to the Gram-negative ones ( $E$. cloacae, S. marcescens) with M. luteus (Gram positive) and S. dysentery (Gram negative) as exceptions. The effective growth decay due to put-AgNPs treatment as shown by rod shaped Bacillus sp. (both B. cereus and B. subtilis) took a
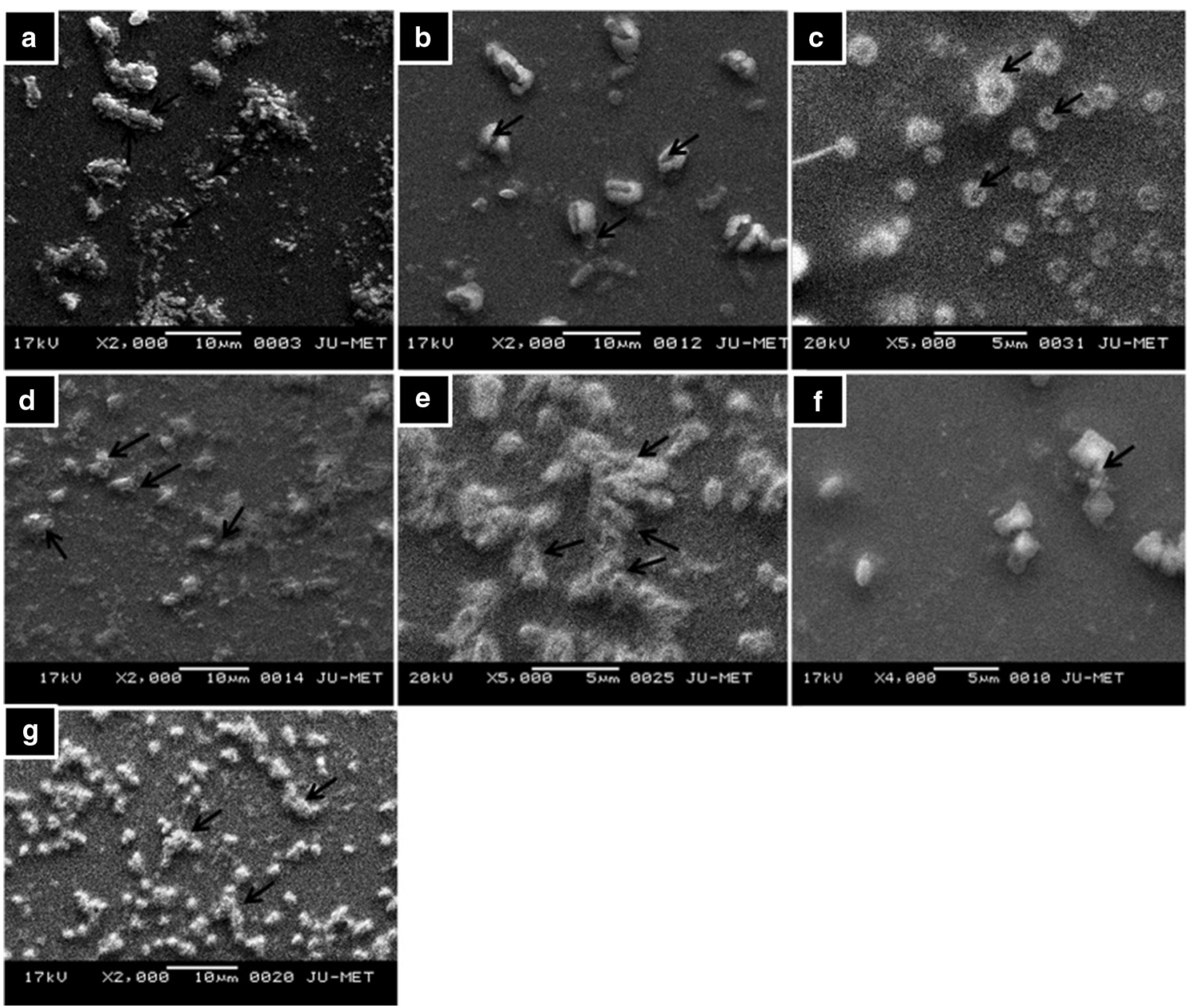

Fig. 7 SEM images showing the bacterial susceptibility towards the put-AgNPs. The distortion and degradation of the cell wall (shown by black arrows) of a Bacillus cereus, $\mathbf{b}$ Bacillus subtilis, $\mathbf{c}$ Micrococcus

luteus, d Staphylococcus aureus, e Enterobacter cloacae, f Serratia marcescens and $\mathbf{g}$ Shigella dysentery are portrayed 

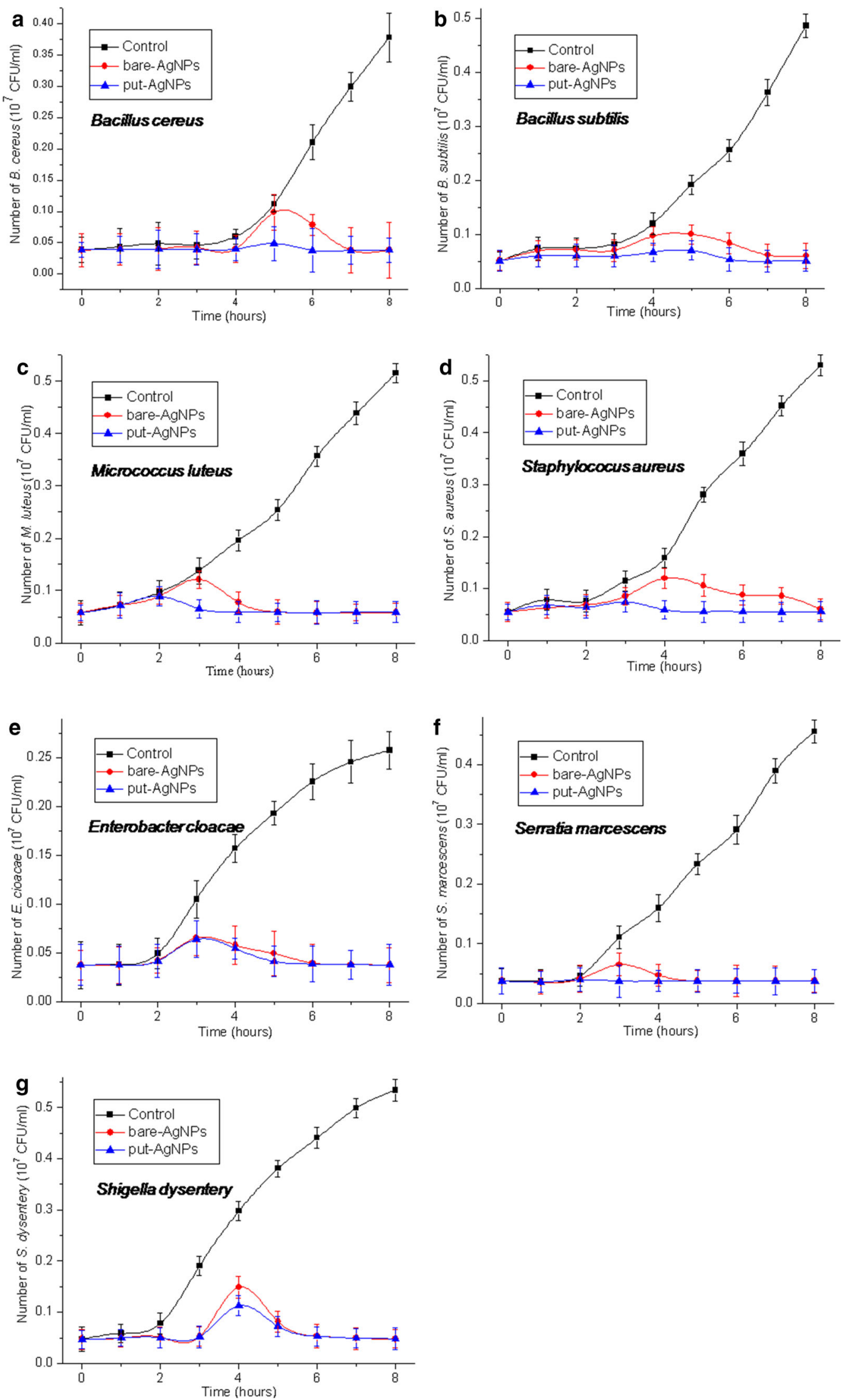
longer time to occur than by the spherical Coccus group of bacteria. This might be effect of the bacterial cellular shape, spherical gaining more surface area of contact. The growth decay curve for the other remaining Gram negative bacterial strains might differ from each other in its affective time due the variation of cell shape, surface proteins and other biomolecules concerned. The inhibition of bacterial growth rate by the capped nanoparticles (put-AgNPs) was much more effective than compared to the bare one which might be due to the biomimic action of the di-amine capping. The capped silver nanoparticles in suspension slowly release some $\mathrm{Ag}^{+}$ions into the bacterial growth media (culture broth) during application of it. These released ions may cause a metal stress to the bacteria, influencing them to recognize and uptake cationic polyamine (Igarashi and Kashiwagi 1999) which are present in the media as capped-AgNPs. Moreover, silver has also been reported to interfere with the sulfhydryl groups of bacterial proteins (both membrane and intracellular ones). Proteins (also in the form of enzymes) are one of the essential biomolecules for cell division, growth and reproduction of living organisms. Consequently, due to the more effective interference by silver ions released from put-AgNPs than from bare-AgNPs (due to biomimic action) with the bacterial proteins, growth, division and reproduction are ceased and inhibited. Thus, bacterial cells may internalize the capped nanosilver (put-AgNPs) expressing biomimic activity and its growth can be ceased effectively with time. This will be lacking in case of bareAgNPs, due to absence of the polyamine. Thus, the inhibition of bacterial growth rate by the capped nanoparticles (put-AgNPs) showed much more effectiveness than compared to the bare one which might be due to the biomimic action of the di-amine capping.

\section{Conclusions}

The present study discloses a successful synthesis of plant natural polyamine (putrescine) capped spherical silver nanoparticles (put-AgNPs) by chemiadsorbtion, attaining a diameter of $10-25 \pm 1.5 \mathrm{~nm}$. It also conveys better bacterial susceptibility towards the newly synthesized capped nanosilver than the bare ones. Consequently, the synthesized polyamine-capped silver nanoparticles proved to be a persuasive antibacterial agent against both Gram-positive and Gram-negative strains of bacteria. The comparative study about the interactions and antibacterial potentiality (observed through MICs) of both types of nanosilver reflects improved bacterial susceptibility by cations present in the capping materials i.e., bare-AgNPs $<$ put-AgNPs. The kinetic study with capped silver nanoparticles reveals a successful bacterial growth rate inhibition which is denotable mainly at their log phase. Thus, it could be concluded that these putrescine-capped silver nanoparticles could be used in developing antimicrobial agents which may find its prospective applications mainly in the field of agronomy, also as packaging materials and water purification.

Acknowledgments Authors acknowledge the Centre for Research in Nanoscience and Nanotechnology, University of Calcutta, for providing instrumental facilities of DLS and zeta measurements and FTIR analysis. MGC and SS acknowledge Jadavpur University for providing University fund for the research work. KG acknowledges Department of Science and Technology, Govt. of India, for the research funding. The authors acknowledge Souryadeep Mukherjee, Assistant Professor, Presidency University, for providing the bacterial strains used in this study.

Open Access This article is distributed under the terms of the Creative Commons Attribution 4.0 International License (http:// creativecommons.org/licenses/by/4.0/), which permits unrestricted use, distribution, and reproduction in any medium, provided you give appropriate credit to the original author(s) and the source, provide a link to the Creative Commons license, and indicate if changes were made.

\section{References}

Abdi G, Salehi H, Khosh-Khui M (2008) Nano silver: a novel nanomaterial for removal of bacterial contaminants in valerian (Valeriana officinalis L.) tissue culture. Acta Physiol Plant 30:709-714

Amato E, Diaz-Fernandez YA, Taglietti A, Pallavicini P, Pasotti L, Cucca L, Milanese C, Grisoli P, Dacarro C, FernandezHechavarria JM, Necchi V (2011) Synthesis, characterization and antibacterial activity against gram positive and gram negative bacteria of biomimetically coated silver nanoparticles. Langmuir 27:9165-9173

Bagni N, Pistocchi R (1991) Uptake and transport of polyamine and inhibitors of polyamine metabolism in plants. In: Slocum RD, Flores HE (eds) Biochemistry and physiology of polyamine in plants. CRC Press, Boca Raton, pp 105-120

Bar H, Bhui DKr, Sahoo GP, Sarkar P, De SP, Misra A (2009) Green synthesis of silver nanoparticles using latex of Jatropha curcas. Colloid Surf A 339:134-139

Feng QL, Wu J, Chen GQ, Cui FZ, Kim TN, Kim JO (2000) Mechanistic study of the antibacterial effect of silver ions on Escherichia coli and Staphylococcus aureus. Biomed Mater Res 52:662-668

Flores HE, Galston AW (1982) Polyamines and plant stress: activation of putrescine biosynthesis by osmotic shock. Science 217:1259-1261

Flores HE, Protacio CM, Signs MW (1989) Primary and secondary metabolism of polyamines in plants. In: Poulton JE, Romeo JT, Conn EE (eds) Plant nitrogen metabolism. Rec Adv Phytochem Plenum Press, New York, pp 329-393

Guggenbichler JP, Boswald M, Lugauer S, Krall T (1999) A new technology of microdispersed silver in polyurethane induces antimicrobial activity in central venous catheters. Infection 27:16-23

Gupta K, Dey A, Gupta B (2013) Plant polyamines in abiotic stress responses. Acta Physiol Plant 35:2015-2036. http:// 
nanocomposix.com/pages/silver-nanoparticles-optical-properties. Accessed on 27 Nov 2015

Gupta B, Gupta K, Huang B (2014) Role of polyamines in plant abiotic stress responses. In: Pessarakli M (ed) Handbook of crop stress physiology. CRC Press, Boca Rotan, pp 369-388

Igarashi K, Kashiwagi K (1999) Polyamine transport in bacteria and yeast. Biochem J 344:633-642

Jain PK, Xiaohua H, Ivan H, Sayed EL, Mostafa (2008) A noble metals on the nanoscale: optical and photothermal properties and some applications in imaging, sensing, biology, and medicine. Acc Chem Res 41:1578-1586

Jung WK, Koo HC, Kim KW, Shin S, Kim SH, Park YH (2008) Antibacterial activity and mechanism of action of the silver ion in Staphylococcus aureus and Escherichia coli. Appl Environ Microbiol 74:2171-2217

Kawahara K, Tsuruda K, Morishita M, Uchida M (2000) Antibacterial effect of silver-zeolite on oral bacteria under anaerobic conditions. Dental Mater 16:452-455

Kemp W (1991) Organic spectroscopy. St Marin's Press Palgrave Pub Ltd, New York

Kittler S, Greulich C, Diendorf J, Koller M, Epple M (2010) Toxicity of silver nanoparticles increases during storage because of slow dissolution under release of silver ions. Chem Mater 22:4548-4554

Liu J, Sonshine DA, Shervani S, Hurt RH (2010) Controlled release of biologically active silver from nanosilver surfaces. ACS Nano 4:6903-6913

Lv Y, Liu H, Wang Z, Liu S, Hao L, Sang Y, Liu D, Wang J, Boughton RI (2009) Silver nanoparticle-decorated porous ceramic composite for water treatment. J Membr Sci 331:50-56

Mandeh M, Omidi M, Rahaie M (2012) In vitro influences of $\mathrm{TiO}_{2}$ nanoparticles on barley (Hordeum vulgare L.) tissue culture. Biol Trace Elem Res 150:376-380

Malvern Instruments Ltd. Zetasizer nano series technical note. http:// www.malvern.co.uk. Accessed 10 May 2014

Mazur M (2004) Electrochemically prepared silver nanoflakes and nanowires. Electrochem Commun 6:400-403

Mohanpuria PN, Rana K, Yadav SK (2008) Biosynthesis of nanoparticles: technological concepts and future applications. J Nanopart Res 10:507-517

Muhling M, Bradford A, Readman JW, Somerfield PJ, Handy RD (2009) An investigation into the effects of silver nanoparticles on antibiotic resistance of naturally occurring bacteria in an estuarine sediment. Mar Environ Res 68:278-283

Nabil AA, Lakshmi PK, Wadu-Mesthrige Kapila, Alexy B, Shahriar M, Gang-yu L (2000) High-resolution atomic force microscopy studies of the Escherichia coli outer membrane: structural basis for permeability. Langmuir 16:2789-2796

Rai MK, Deshmukh SD, Ingle AP, Gade AK (2012) Silver nanoparticles: the powerful nanoweapon against multidrugresistant bacteria. J Appl Microbiol 112:841-852
Rao CNR, Kulkarni GU, Thomas PJ, Peter PE (2002) Size-dependent chemistry: properties of nanocrystals. Chem Eur J 8:28-35

Roduner E (2006) Size matters: why nanomaterials are different. Chem Soc Rev 35:583-592

Roy K, Sarkar CK, Ghosh CK (2015) Plant-mediated synthesis of silver nanoparticles using parsley (Petroselinum crispum) leaf extract: spectral analysis of the particles and antibacterial study. Appl Nanosci 5:945-951

Saha S, Sarkar J, Chattopadhyay D, Patra S, Chakraborty A, Acharya K (2010) Production of silver nanoparticles by a phytopathogenic fungus Bipolaris nodulosa and its antimicrobial activity. Dig J Nanomater Biostruct 5:887-895

Saha S, Chattopadhyay D, Acharya K (2011) Preparation of silver nanoparticles by bio-reduction using Nigrospora oryzae culture filtrate and its antimicrobial activity. Dig J Nanomater Biostruct 6:1526-1535

Saha S, Gupta B, Gupta K, Ghosh Chaudhuri M (2015) Natural polyamine capped silver nanoparticles used as a decontaminant in plant tissue culture. J Nanotrends 17:31-36

Schoefield CL, Haines AH, Field RA, Russel DA (2006) Silver and gold glyconanoparticles for colorimetric bioassays. Langmuir 22:6707-6711

Schuber F (1989) Influence of polyamines on membrane functions. Biochem J 260:1-10

Silverstein RM (2012) Spectroscopy chemistry NMR FTIR MS. Qurrota A'yun Thoyyibah Pub

Sondi I, Salopek-Sondi B (2004) Silver nanoparticles as antimicrobial agent: a case study on E. coli as a model for gram-negative bacteria. J Colloid Interface Sci 275:177-182

Tian JK, Wong KY, Ho CM, Lok CN, Yu WY, Che CM, Chiu JF, Tam PKH (2007) Topical delivery of silver nanoparticles promotes wound healing. ChemMedChem 2:129-136

Tolaymat TM, EI Badawy AM, Genaidy A, Scheckel KG, Luxton TP, Suidan M (2010) An evidence-based environmental perspective of manufactured silver nanoparticle in synthesis and applications: a systematic review and critical appraisal of peer-reviewed scientific papers. Sci Total Environ 408:999-1006

Vijayaraghavan K, Nalini SPK (2010) Biotemplates in the green synthesis of silver nanoparticles. Biotechnol J 5:1098-1110

Vo Ke Thanh N, Phuong Phong NT (2009) Investigation of antibacterial activity of cotton fabric incorporating nano silver colloid. J Phys: Conf Ser 187:012-072

Xie J, Lee JY, Wang DIC, Ting YP (2007) Silver nanoplates: from biological to biomimetic synthesis. ACS Nano 1:429-439

Young ND, Galston AW (1983) Putrescine and acid stress: induction of arginine decarboxylase activity and putrescine accumulation by low pH. Plant Physiol 71:767-771 